\title{
Cardiovascular and respiratory dysfunction in chronic obstructive pulmonary disease complicated by impaired peripheral oxygenation
}

This article was published in the following Dove Press journal: International Journal of COPD

II February 2015

Number of times this article has been viewed

\author{
Ming-Lung Chuang',2 \\ Shih-Feng Huang' \\ Chun-Hung Su',3 \\ 'Division of Pulmonary \\ Medicine and Department \\ of Critical Care Medicine, ${ }^{2}$ School \\ of Medicine, ${ }^{3}$ Division of Cardiology \\ and Department of Internal \\ Medicine, Chung Shan Medical \\ University Hospital, Taichung, Taiwan \\ Republic of China
}

Background: Impaired peripheral oxygenation (IPO)-related variables readily achieved with cardiopulmonary exercise testing (CPET) represent cardiovascular dysfunction. These variables include peak oxygen uptake $\left(\dot{\mathrm{VO}}_{2}\right)<85 \%$ predicted, anaerobic threshold $<40 \% \dot{\mathrm{VO}}_{2 \max }$ predicted, $\mathrm{V}_{2}$-work rate slope $<8.6 \mathrm{~mL} /$ watt, oxygen pulse $<80 \%$ predicted, and ventilatory equivalents for $\mathrm{O}_{2}$ and $\mathrm{CO}_{2}$ at nadir of $>31$ and $>34$, respectively. Some of these six variables may be normal while the others are abnormal in patients with chronic obstructive pulmonary disease (COPD). This may result in confusion when using the interpretation algorithm for diagnostic purposes. We therefore hypothesized that patients found to have abnormal values for all six variables would have worse cardiovascular function than patients with abnormal values for none or some of these variables.

Methods: In this cross-sectional comparative study, 58 COPD patients attending a university teaching hospital underwent symptom-limited CPET with multiple lactate measurements. Patients with abnormal values in all six IPO-related variables were assigned to an IPO group while those who did not meet the requirements for the IPO group were assigned to a non-IPO group. Cardiovascular function was measured by two-dimensional echocardiography and $\Delta$ lactate $/ \Delta \dot{\mathrm{VO}}_{2}$, and respiratory dynamics were compared between the two groups.

Results: Fourteen IPO and 43 non-IPO patients were entered into the study. Both groups were similar with regard to left ventricular ejection fraction and right ventricular morphology $(P>0.05$ for both). At peak exercise, both groups reached a similar heart rate level and $\Delta$ lactate $/ \Delta \dot{\mathrm{V}} \mathrm{O}_{2}$. The IPO patients had an unfavorable dead space to tidal volume ratio, mean inspiratory tidal flow, and shallow breathing $(P<0.05-P<0.001)$.

Conclusion: Our IPO and non-IPO patients with COPD had similar cardiovascular performance at rest and at peak exercise, indicating that IPO variables are non-specific for cardiovascular function in these patients. COPD patients with full IPO variables have more deranged ventilatory function.

Keywords: dead space ventilation, dynamic hyperinflation, air-trapping, inspiratory tidal flow rate, lung function, cardiovascular function, oxygen pulse

\section{Introduction}

Impaired peripheral oxygenation (IPO) of exercising muscles is caused by impaired circulation and/or mitochondrial function and a low arterial oxygen content, such that oxygen cannot flow adequately to myocytes. ${ }^{1}$ The mechanisms of IPO are quite different from those of hypoxemia, mostly due to respiratory pathology. IPO can seriously limit patients' ability to perform certain activities of daily living, and the impact of related symptoms can be quite significant. ${ }^{2}$

Clinicians tend to screen for the causes of exertional dyspnea using non-invasive cardiopulmonary exercise testing (CPET). ${ }^{1,3-5}$ IPO-related variables obtained from
Correspondence: Ming-Lung Chuang ( \#I 10, Section I, Chien-Kuo North Road, South District, Taichung 4020I, Taiwan, Republic of China Tel +88 6424739595 Ext 347। 8 $\mathrm{Fax}+886424739220$

Email yuan 1007@ms36.hinet.net 
CPET include peak oxygen uptake $\left(\dot{\mathrm{V}}_{2}\right)<85 \%$ predicted, anaerobic threshold $<40 \% \dot{\mathrm{VO}}_{2 \max }$ predicted, $\dot{\mathrm{VO}}_{2}$-work rate slope $<8.6 \mathrm{~mL} /$ watt, oxygen pulse $<80 \%$ predicted, and ventilatory equivalents for $\mathrm{O}_{2}$ and $\mathrm{CO}_{2}$ at nadirs of $>31$ and $>34$, respectively. ${ }^{1}$

These six individual IPO variables represented cardiovascular parameters, but are reported to be non-specific in discriminating chronic obstructive pulmonary disease (COPD) with and without chronic circulatory changes ${ }^{6-8}$ using invasive pulmonary artery catheterization. ${ }^{7,8}$ However, at present, it is not clear how we can effectively interpret the algorithm since some of the six variables may be normal while others are abnormal. We hypothesized that patients with all six variables found to be abnormal would have worse cardiovascular function than those with none or some having abnormal values. Our approach in this study was oriented toward interpretation of the CPET report, and we found that this approach may be more useful when evaluating IPOrelated variables with regard to their clinical implications.

\section{Materials and methods Study design}

In this cross-sectional comparative study, the patients were divided into three groups based on six variables obtained from CPET. Patients with abnormal values for all six variables were assigned to a full IPO group, those with normal values for all six variables were assigned to a non-IPO group, and the remaining patients were assigned to an intermediate IPO group. Two-dimensional echocardiography, changes $(\Delta)$ in lactate, $\Delta$ in oxygen uptake $\left(\dot{\mathrm{VO}}_{2}\right)$, a parameter of cardiovascular function, ${ }^{9}$ and arterial $\mathrm{pH}$ values were compared across the groups. Arterial pH values should be lower in patients with cardiovascular dysfunction than in those without cardiovascular dysfunction performing at the same exercise intensity or cardiovascular stress level. A comparison of respiratory dynamics was performed across the groups. The institutional review board of Chung Shan Medical University Hospital approved the study (approval number CS11144) and all participants provided their written informed consent. This trial is registered with the number CSH-2012-C-23 at Chung Shan Medical University Hospital, Taichung, Taiwan.

\section{Subjects}

Global Initiative for Chronic Obstructive Lung Disease criteria were used to diagnose COPD. ${ }^{10}$ Adult patients with COPD who underwent lung function tests were enrolled only if their forced expired volume in one second $\left(\mathrm{FEV}_{1}\right)$ was $<80 \%$ of the predicted value and their $\mathrm{FEV}_{1}$ /forced vital capacity ratio was $<70 \%$. If they agreed, they performed symptomlimited incremental CPET with arterial blood gas analysis and lactate measurements. All patients were clinically stable and had had no significant changes in medication in the month prior to performing the tests. Patients were excluded if they had significant comorbidities, such as left ventricular failure, renal failure, cancer, significant anemia, peripheral arterial occlusive disease, uncontrolled diabetes mellitus, or hypertension, or if they were participating in any physical training program during the study period.

\section{Protocols and measurements}

\section{Pulmonary function testing}

$\mathrm{FEV}_{1}$, total lung capacity, and residual volume were measured by spirometry and plethysmography (6200 Autobox DL, Yorba Linda, CA, USA, or MasterScreen ${ }^{\mathrm{TM}}$ Body, Carefusion, Würzburg, Germany) at body temperature, ambient atmospheric pressure, and fully saturated, using the best of three technically satisfactory readings. ${ }^{11-13}$ The diffusing capacity for carbon monoxide $\left(\mathrm{D}_{\mathrm{L}} \mathrm{CO}\right)$ was measured by the single-breath technique. Direct maximum voluntary ventilation (MVV) was calculated from a 12-second maneuver of rapid and deep breathing as recommended for patients with COPD.${ }^{14}$ All lung function data were obtained after inhaling $400 \mu \mathrm{g}$ of fenoterol $\mathrm{HCl}$.

\section{Maximum cardiopulmonary exercise testing}

After acclimating to a computer-controlled and electronicbrake cycle ergometer (Medical Graphics, St Paul, MN, USA) and following a 2-minute rest period, each patient began a 2-minute period of unloaded cycling followed by a ramp-pattern exercise test to the limit of tolerance. Work rate was selected at a slope of 5-20 watts per minute based on a derived protocol formula. ${ }^{15}$ Twelve-lead electrocardiography, $\dot{\mathrm{VO}}_{2}(\mathrm{~mL} / \mathrm{min}), \dot{\mathrm{V} C O}{ }_{2}(\mathrm{~mL} / \mathrm{min})$, minute ventilation, pulse rate, and oxyhemoglobin saturation were continuously measured. Blood pressure was recorded at the end of each minute and at the point where the patient reported having reached peak exercise. A dyspnea score was obtained using the Borg scale by asking the patients about their dyspnea levels while they were performing the ramp-pattern exercise at the end of each minute and at peak exercise. Please refer to Chuang and $\mathrm{Lin}^{16}$ for the anaerobic threshold, oxyhemoglobin saturation, calibrations of the pneumotachograph and $\mathrm{O}_{2}$ and $\mathrm{CO}_{2}$ analyzers, and $\dot{\mathrm{VO}}_{2 \text { peak }}$ prediction equations.

The $\dot{\mathrm{VO}}_{\text {2peak }}$ achieved by patients was the highest recorded value averaged over the last 15 seconds of loaded exercise and designated as $\dot{\mathrm{V}}{ }_{2 \text { peak }}$ or $\dot{\mathrm{V}}{ }_{2 \max }{ }^{15}$ 
Maximum exercise effort achieved was a prerequisite for final analysis. ${ }^{4,5,17}$ Each criterion at peak exercise, such as respiratory exchange ratio $\geq 1.09$, heart rate $\geq 85 \%$ of predicted maximum, $\mathrm{pH} \leq 7.35$, bicarbonate $\left(\mathrm{HCO}_{3}^{-}\right)$concentration $\leq 21 \mathrm{mEq} / \mathrm{L}$, change in $\mathrm{HCO}_{3}{ }^{-}$concentration between rest and peak exercise $\geq 4 \mathrm{mEq} / \mathrm{L}$, and change in lactate concentration between rest and peak exercise $\geq 4 \mathrm{mEq} / \mathrm{L}$ represented one point. The maximum effort level was scored from 1 to 6 points. The accumulated points, representing the effort level of exercise, were compared across the groups.

Exercise intensity or cardiovascular stress level was defined as follows:

Exercise intensity or $=\frac{\text { Heart rate at peak exercise }}{\text { Heart rate predicted maximum }}$

where heart rate predicted maximum $=220$ - age.

Ventilatory limitation was defined as either $<30 \%$ or $<11-15 \mathrm{~L} /$ min breathing reserve, calculated as follows: ${ }^{1,4}$

$$
\text { Breathing reserve }=1-\dot{\mathrm{V}}_{\text {Epeak }} / \text { direct MVV }
$$

where $\dot{\mathrm{V}}_{\text {Epeak }} /$ direct MVV indicates $\dot{\mathrm{V}}_{\mathrm{E}}$ demand/capacity ratio.

$$
\begin{aligned}
& \text { Mean inspiratory } \\
& \text { tidal flow rate }
\end{aligned}=\frac{\text { Tidal volume }\left(\mathrm{V}_{\mathrm{T}}\right)(\mathrm{L})}{\text { Inspiratory time }(\text { seconds })^{18}}
$$

$$
\begin{aligned}
& \text { Rapid shallow } \\
& \text { breathing index }
\end{aligned}=\frac{\text { Breathing frequency }(\text { breath } / \mathrm{min})}{\mathrm{V}_{\mathrm{T}}(\mathrm{L})^{19}}
$$

\section{Two-dimensional echocardiography}

Two-dimensional echocardiography (iE33, Philips, Seattle, WA, USA) was performed within 4 weeks before or after CPET by two experienced cardiologists who were blinded to the clinical data, lung function, and CPET reports. If there were acute exacerbations of COPD in the time between the two tests, one of the tests would be postponed. Parasternal, apical, and subcostal studies were conducted, and the definition of cor pulmonale was used according to previous reports..$^{20,21}$

\section{Arterial blood sampling and lactate determination}

Brachial artery blood samples were drawn via an arterial catheter connected to a pressure transducer within the last 15 seconds of each minute after the start of exercise to the peak of exercise. ${ }^{22}$ Whole blood lactate was also analyzed (YSI Inc, Yellow Springs, OH, USA).
At the peak of exercise, the dead space to tidal volume ratio $\left(\mathrm{V}_{\mathrm{D}} / \mathrm{V}_{\mathrm{T}}\right)$ was calculated using a standard formula. ${ }^{23}$

The slopes of lactate as a function of $\dot{\mathrm{VO}}_{2}$ calculated using linear regression $\left(\Delta\right.$ lactate $\left./ \Delta \dot{\mathrm{V}} \mathrm{O}_{2}\right)$ were compared across the groups.

\section{Statistical analysis}

The data are shown as the mean \pm standard deviation or median (interquartile range). Analysis of variance was initially considered for comparing the means across the groups; however, there were no patients in the non-IPO group. Therefore, only two groups were established. Thus, the unpaired-t-test or Mann-Whitney $U$-test was used to compare the means between the two independent groups. Fisher's Exact test for contingency tables was used to compare the stages of COPD between the two groups. A $P<0.05$ was considered to be statistically significant, and $P<0.1$ but $P>0.05$ was considered to have a trend to be significant. ${ }^{24}$ All statistical procedures were performed using SAS software package version 9.3 (SAS Institute Inc, Cary, NC, USA).

\section{Results}

Fifty-eight consecutive male patients of mean age 64.6 \pm 6.1 years were enrolled in the study. After excluding one patient who did not reach the maximum exercise level when performing CPET, 14 patients were assigned to the IPO group, no patients were assigned to the non-IPO group, and the other 43 patients were assigned to the intermediate IPO group (Table 1). For the sake of simplicity, the latter two groups were deemed to be non-IPO groups. Table 2 presents the distribution of the six variables regarding the abnormal values for the non-IPO groups. The IPO and non-IPO groups had similar stages of COPD severity. The IPO group had more hyperinflated lungs and lower $\mathrm{D}_{\mathrm{L}} \mathrm{CO}(P=0.05$ to $P<0.01$; Table 1). Both groups performed at a similar level of maximum exercise effort.

No patient experienced an acute exacerbation in the time interval between echocardiography and CPET. Table 3 shows that the two-dimensional echocardiographic findings, including left ventricular ejection fraction and right ventricular morphology, were similar between the two groups (all $P>0.05$ ).

The heart rate percentage predicted maximum at peak exercise was similar between the two groups (IPO group: $77 \% \pm 14 \%$ versus non-IPO group: $82 \% \pm 10 \%, P=0.26$ ). $\mathrm{pH}$ levels were higher at anaerobic threshold and peak exercise in the IPO group ( $P=0.007$ and $P=0.0007$, respectively), with a smaller decrease in $\mathrm{HCO}_{3}^{-}$concentration and increase in 
Table I Variables related to impaired peripheral oxygenation and selected clinical characteristics and lung function test data in patients with COPD

\begin{tabular}{|c|c|c|c|}
\hline & IPO & Non-IPO & $P$-value \\
\hline & $(n=14)$ & $(n=43)$ & \\
\hline Age, years & $62.9 \pm 5.9$ & $65.2 \pm 6.1$ & NS \\
\hline Height, cm & $168.2 \pm 6.1$ & $164.3 \pm 5.8$ & 0.05 \\
\hline Body mass index, $\mathrm{kg} / \mathrm{m}^{2}$ & $21.3 \pm 3.2$ & $22.9 \pm 3.6$ & 0.01 \\
\hline Triceps skin thickness, mm & $6 \pm 2.7$ & $8.7 \pm 5.3$ & 0.02 \\
\hline Cigarette, pack-years & $38.5 \pm 17.6$ & $42.9 \pm 18.4$ & NS \\
\hline Hemoglobin, g/dL & $14.3 \pm 2.1$ & $\mid 5.2 \pm 1.3$ & NS \\
\hline FVC (L) & $2.58 \pm 0.65$ & $2.63 \pm 0.73$ & NS \\
\hline $\mathrm{FEV}_{1}(\mathrm{~L})$ & $1.21 \pm 0.64$ & $1.3 \pm 0.48$ & NS \\
\hline $\mathrm{FEV}_{1} / \mathrm{FVC}, \%$ & $48 \pm 18$ & $50 \pm 12$ & NS \\
\hline COPD stage I/II/III/IV, n & $1 / 4 / 6 / 3$ & $2 / 23 / 15 / 3$ & NS \\
\hline TLC, L & $6.99 \pm 1.07$ & $6.26 \pm 0.87$ & 0.04 \\
\hline $\mathrm{RV}, \mathrm{L}$ & $4.35 \pm 0.97$ & $3.5 \pm 0.69$ & 0.01 \\
\hline RV/TLC, \% & $62 \pm 9$ & $56 \pm 9$ & 0.05 \\
\hline FRC, L & $5.34 \pm 1$ & $4.5 I \pm 0.79$ & 0.02 \\
\hline $\mathrm{D}_{\mathrm{L}} \mathrm{CO} / \mathrm{D}_{\mathrm{L}} \mathrm{CO} \mathrm{pred}_{\text {pro }} \%$ & $57 \pm 21$ & $79 \pm 19$ & 0.003 \\
\hline \multicolumn{4}{|l|}{ IPO criteria } \\
\hline$\dot{\mathrm{V}} \mathrm{O}_{2 \text { peak }} /$ pred $\dot{\mathrm{V}} \mathrm{O}_{2 \max }, \%(\geq$ or $<85 \%)$ & $47 \pm 12$ & $77 \pm 15$ & \\
\hline Anerobic threshold/pred $\dot{\mathrm{V}} \mathrm{O}_{2 \max }(\geq$ or $<40 \%)$ & $24 \pm 6$ & $37 \pm 10$ & \\
\hline$\dot{\mathrm{V}} \mathrm{O}_{2}$-work rate ratio, $\mathrm{mL} /$ watt $(\geq$ or $<8.6)$ & $5.6 \pm 2.5$ & $8 \pm 1.5$ & \\
\hline Oxygen pulse $_{\text {peak }}, \%$ pred maximum $(\geq$ or $<80 \%)$ & $60 \pm 12$ & $95 \pm 18$ & \\
\hline Ventilatory equivalent for $\mathrm{O}_{2 \text { nadir }}(\leq$ or $>34)$ & $40.4 \pm 5.4$ & $34.2 \pm 6.5$ & \\
\hline Ventilatory equivalent for $\mathrm{CO}_{2 \text { nadir }}(\leq$ or $>3 \mathrm{I})$ & $41.8 \pm 4.9$ & $32.5 \pm 5.7$ & \\
\hline Maximum exercise effort level, point (AU) & $1.9 \pm 1.8$ & $3.1 \pm 2.1$ & NS \\
\hline
\end{tabular}

Notes: Groups were compared using the unpaired-t-test. Between-group comparisons of RV were performed using the Mann-Whitney U-test.

Abbreviations: COPD, chronic obstructive pulmonary disease; IPO, impaired peripheral oxygenation; non-IPO, patients failing to fit IPO criteria; FVC, forced vital capacity; FEV , forced expired volume in one second; $D_{L} C O$, diffusing capacity for carbon monoxide; AU, arbitrary unit; TLC, total lung capacity; RV, residual volume; FRC, functional residual capacity; NS, not statistically significant; pred, predicted.

lactate concentration $(3.6 \pm 0.5 \mathrm{mmol} / \mathrm{L}$ versus $5.7 \pm 0.3 \mathrm{mmol} / \mathrm{L}$, $P=0.02$, and $1.4 \pm 1.8 \mathrm{mmol} / \mathrm{L}$ versus $2.9 \pm 1.8 \mathrm{mmol} / \mathrm{L}, P=0.003$, respectively). The slopes of $\Delta$ lactate $/ \Delta \dot{\mathrm{V} O}{ }_{2}$ were similar between the two groups (2.4 [error 0.15 ] versus 2.3 [error 0.1 ] $\mathrm{mmol} / \mathrm{L}$, not statistically significant).

The IPO group had a rapid increase in $\dot{V}_{\mathrm{E}}$ but slower expansion of tidal volume in response to exercise (Figure 1A and D, both $P<0.05$ ). The IPO group had a significantly lower $\dot{\mathrm{V}}_{\mathrm{E}}$ demand/capacity ratio $(P<0.05)$ with slower inspiratory tidal flow and lower $\mathrm{V}_{\mathrm{T}}$ /total lung capacity expansion at both anaerobic threshold and peak exercise (Figure 1B, C, and E, $P<0.01$ and $P<0.05$, and both $P \leq 0.001$, respectively) and higher $\mathrm{V}_{\mathrm{D}} / \mathrm{V}_{\mathrm{T}}$, rapid shallow breathing index, and Borg $/ \dot{\mathrm{V}} \mathrm{O}_{2}$ in the IPO group at peak exercise (Figure $1 \mathrm{~F}-\mathrm{H}, P<0.001$, $P<0.05$, and $P<0.01$, respectively).

\section{Discussion}

In this study, COPD patients with full IPO and those with nonIPO had similarly impaired forced vital capacity, $\mathrm{FEV}_{1}$, and COPD severity (Table 1). Both groups had different exercise capacity with very different cardiovascular exercise variables (Table 1), but were similar in terms of cardiovascular function measured by two-dimensional echocardiography and $\Delta$ lactate $/ \Delta \dot{\mathrm{VO}}{ }_{2}$ (Table 3 ). These findings suggest that cardiovascular variables on CPET cannot predict cardiac function morphologically. We therefore further differentiated the mechanism of full IPO and non-IPO during exercise. We found that patients with IPO had much poorer airflow and lung expansion and a greater perception of breathlessness (Figure 1).

Left ventricular performance has been reported not to be impaired in COPD patients. ${ }^{25}$ A previous study reported that there were no differences in oxygen uptake, work rate, oxygen pulse, and heart rate at peak exercise between patients with and without pulmonary arterial hypertension. ${ }^{8}$ The authors concluded that ventilatory limitation itself was the primary factor causing exercise intolerance in COPD patients. Circulatory impairment is not usually a limiting factor for exercise intolerance in patients with COPD unless complications of severe pulmonary hypertension are involved. ${ }^{26}$ The cardiovascular response to exercise 
Table 2 Distribution of the six variables regarding IPO criteria for the non-IPO group $(n=43 *)$

\begin{tabular}{|c|c|}
\hline Subjects having & $\bar{n}$ \\
\hline Any 5 abnormal of 6 criteria & 9 \\
\hline Any 4 abnormal of 6 criteria & 7 \\
\hline Any 3 abnormal of 6 criteria & 9 \\
\hline Any 2 abnormal of 6 criteria & 16 \\
\hline Any I abnormal of 6 criteria & I \\
\hline$\dot{\mathrm{V}} \mathrm{O}_{2 \text { peak }} /$ pred $\dot{\mathrm{V}} \mathrm{O}_{2 \max }<85 \%$ & 29 \\
\hline Anerobic threshold/pred $\dot{\mathrm{V}} \mathrm{O}_{2 \max }<40 \%$ & 24 \\
\hline$\dot{\mathrm{V}} \mathrm{O}_{2}$-work rate ratio $<8.6 \mathrm{~mL} /$ watt & 25 \\
\hline Oxygen pulse $_{\text {peak }} \%$ pred maximum $<80 \%$ & 8 \\
\hline Ventilatory equivalent for $\mathrm{O}_{2 \text { nadir }}>31$ & 24 \\
\hline Ventilatory equivalent for $\mathrm{CO}_{2 \text { ndir }}>34$ & 12 \\
\hline
\end{tabular}

Notes: *Technical difficulty was encountered in one subject. IPO indicates impaired peripheral oxygenation or patients with six variables in the abnormal range; non-IPO indicates patients failing to fit IPO criteria and having from one criterion with an abnormal value to five criteria with abnormal values. The six criteria were $\dot{\mathrm{V}} \mathrm{O}_{2 \text { peak }}$ ' pred $\dot{\mathrm{V}} \mathrm{O}_{2 \max }<85 \%$, anerobic threshold/pred $\dot{\mathrm{V}} \mathrm{O}_{2 \max }<40 \%, \dot{\mathrm{V}} \mathrm{O}_{2}$-work rate ratio $<8.6 \mathrm{~mL} /$ watt, oxygen pulse peak $\%$ pred maximum $<80 \%$, ventilatory equivalent for $\mathrm{O}_{2 \text { nadir }}>3 \mathrm{I}$, and ventilatory equivalent for $\mathrm{CO}_{2 \text { nadir }}>34$

Abbreviations: IPO, impaired peripheral oxygenation; pred, predicted.

was constrained, but not impaired, by dynamic hyperinflation or intrathoracic pressure swings limiting ventilation in COPD patients. ${ }^{27-29} \mathrm{~A}$ study using multiple regression analysis showed that ventilatory inefficiency was not caused by oxygen uptake, work rate, oxygen pulse, or circulatory power at peak exercise, but was related to expiratory flow limitations and dynamic hyperinflation, ${ }^{30}$ which is consistent with other reports. ${ }^{31,32}$ Although all of the variables found in previous reports were comprehensive, they cannot be directly used when interpreting a CPET report. Our approach to the present study was oriented toward interpretation of the CPET.
We did not use pulmonary arterial hypertension as a study criterion because of the invasiveness of pulmonary arterial catheterization. Instead, we attempted to use the six noninvasive variables relating to circulatory function to categorize our COPD patients. We found that the circulatory function of the IPO patients was similar to that of the non-IPO patients according to a two-dimensional echocardiography study and by utilizing the slope of $\Delta$ lactate/ $\Delta \dot{\mathrm{V}} \mathrm{O}_{2}$, which is a marker of cardiovascular impairment. ${ }^{30}$ In addition, relatively low changes in $\mathrm{HCO}_{3}{ }^{-}$and lactate concentrations and higher $\mathrm{pH}$ levels at peak exercise in the IPO group did not support cardiovascular limitations as being the primary factor of exercise limitation.

Resting $\mathrm{FEV}_{1}, \mathrm{D}_{\mathrm{L}} \mathrm{CO}$, peak inspiratory pressure, and exertional maximum $\dot{\mathrm{V}}_{\mathrm{E}}$ play a pivotal role in exercise intolerance in patients with COPD. ${ }^{33,34}$ In the present study, the IPO group showed a lower $\dot{\mathrm{V}}_{\mathrm{E}}$ demand/capacity, probably due to the slower inspiratory tidal flow not able to adequately increase $\dot{V}_{E}$ further in response to exercise, thereby reaching the ventilatory limit at an earlier stage. The slower inspiratory tidal flow and poorer tidal volume expansion might be due to higher tension of the diaphragm caused by increased $V_{D} / V_{T}$ when approaching peak exercise (Figure 2) This notion is supported by studies in lung volume reduction surgery and bronchodilator use showing decreases in $\mathrm{V}_{\mathrm{D}} / \mathrm{V}_{\mathrm{T}}$ resulting in airflow improvement. ${ }^{31,32}$ Increased $V_{D} / V_{T}$ contributes to dynamic hyperinflation, ${ }^{35}$ thereby resulting in more rapid shallow breathing and a greater perception of dyspnea (Figure $1 \mathrm{G}$ and $\mathrm{H}$ ). In the present study, a strong statistical power of 0.98 for $\mathrm{V}_{\mathrm{D}} / \mathrm{V}_{\mathrm{T}}$ was estimated, given 14 subjects with a mean $\mathrm{V}_{\mathrm{D}} / \mathrm{V}_{\mathrm{T}}$ of $0.51 \pm 0.09$ in the IPO group and of $0.4 \pm 0.09$ in the non-IPO group, and the probability of type I error of 0.05 .

Table 3 Two-dimensional echocardiography results

\begin{tabular}{|c|c|c|c|}
\hline \multirow[t]{2}{*}{ Variable } & \multirow{2}{*}{$\frac{\text { IPO }}{\left(n=14^{\ddagger}\right)}$} & \multirow{2}{*}{$\frac{\text { Non-IPO }}{\left(n=43^{\ddagger}\right)}$} & \multirow[t]{2}{*}{ P-value } \\
\hline & & & \\
\hline Left ventricular ejection fraction, \% & $69 \pm 5$ & $67 \pm 6$ & NS \\
\hline \multicolumn{4}{|l|}{ Apical four-chamber view*, yes/no } \\
\hline$E D R V>15 \mathrm{~cm}^{2}$ & $3 / 9$ & $15 / 23$ & NS \\
\hline ESRV $>10 \mathrm{~cm}^{2}$ & $0 / 12$ & $5 / 33$ & NS \\
\hline \multicolumn{4}{|l|}{ Subcostal four-chamber view*, yes/no } \\
\hline$E D R V>13 \mathrm{~cm}^{2}$ & $6 / 6$ & $28 / 10$ & NS \\
\hline$E S R V>8 \mathrm{~cm}^{2}$ & $7 / 5$ & $15 / 23$ & NS \\
\hline \multicolumn{4}{|l|}{ Long and short axes view*, yes/no } \\
\hline Paradoxical motion of interventricular septum & $0 / 12$ & $2 / 36$ & NS \\
\hline Right ventricular free wall thickness $>4 \mathrm{~mm}$ & $10 / 2$ & $31 / 7$ & NS \\
\hline Tricuspid regurgitation*, yes/no & $8 / 4$ & $30 / 8$ & NS \\
\hline Pulmonary regurgitation*, yes/no & $0 / 12$ & $3 / 37$ & NS \\
\hline
\end{tabular}

Notes: ${ }^{\ddagger}$ Some missing data. *The definitions of EDRV and ESRV were from Bertoli et al ${ }^{20}$ and Danchin et al. ${ }^{21}$

Abbreviations: IPO, impaired peripheral oxygenation; ED, end-diastolic; RV, right ventricular; ES, end-systolic; NS, not statistically significant. 
A

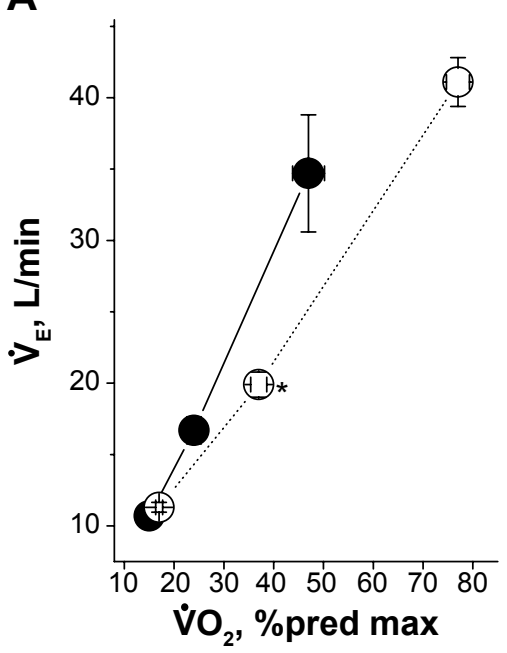

D

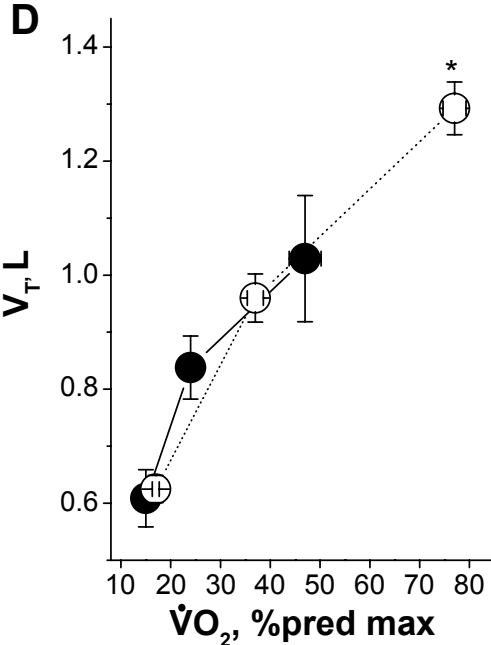

B

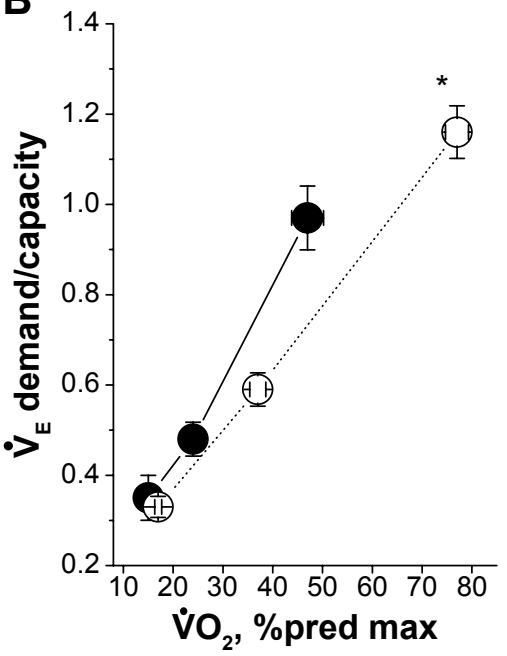

E

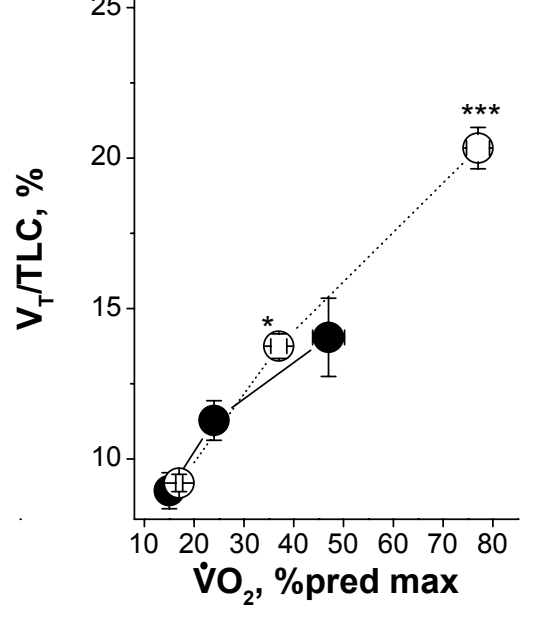

C

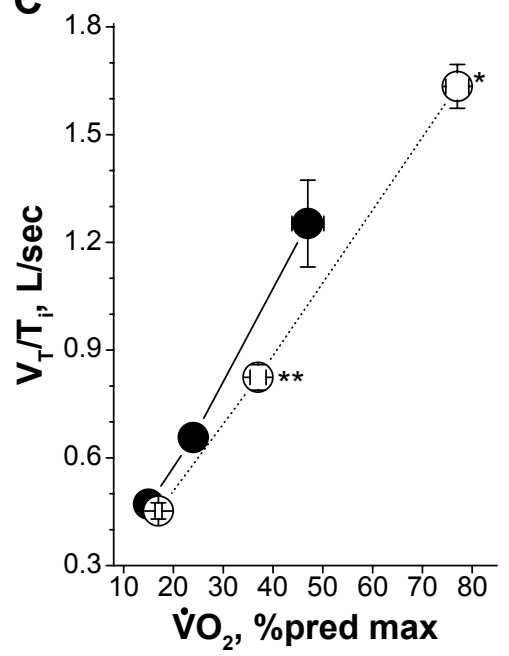

F

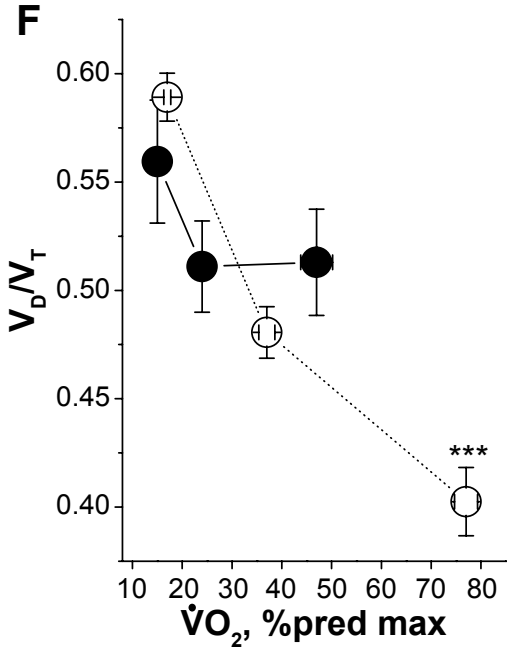

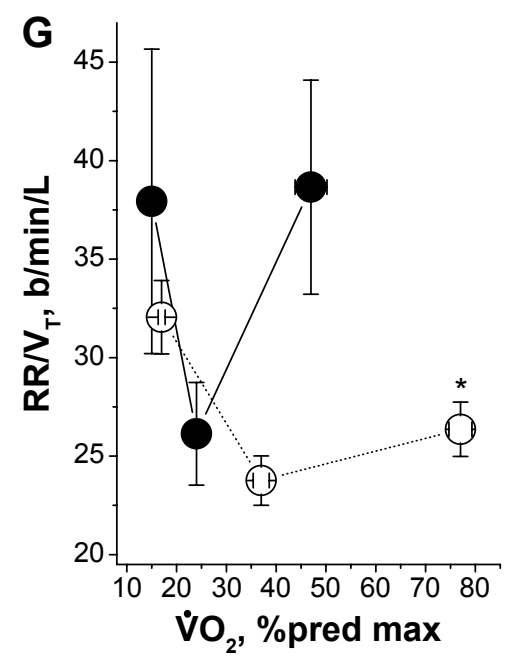

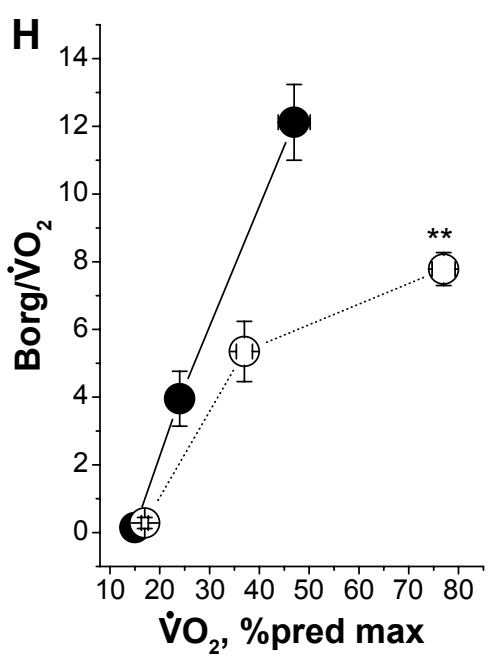

Figure I Findings in I4 patients with COPD complicated by IPO (solid line and solid circle symbol) and 43 patients with COPD complicated by non-IPO (dashed line and open circle symbol) performing incremental cardiopulmonary exercise testing.

Notes: $(\mathbf{A})$ Minute ventilation $\left(\mathrm{V}_{\mathrm{E}}\right)$ as a function of $\mathrm{VO}_{2} \%$ predicted maximum. (B) $\mathrm{VE}$ demand/capacity ratio as a function of $\mathrm{VO}_{2} \%$ predicted maximum. (C) Tidal volume/ inspiratory time $\left(\mathrm{V}_{\mathrm{T}} / \mathrm{T}_{\mathrm{i}}\right)$ indicating mean inspiratory flow rate as a function of $\dot{\mathrm{V}} \mathrm{O}_{2} \%$ predicted maximum. (D) Tidal volume $\left(\mathrm{V}_{\mathrm{T}}\right)$ as a function of oxygen uptake $\left(\dot{\mathrm{V}} \mathrm{O}_{2}\right) \%$ predicted maximum. (E) $\mathrm{V}_{\mathrm{T}}$ /total lung capacity ratio $\left(\mathrm{V}_{\mathrm{T}} / \mathrm{TLC}\right)$ indicating lung expansion as a function of $\mathrm{V}_{2} \%$ predicted maximum. $(\mathbf{F})$ Dead space/tidal volume ratio $\left(\mathrm{V}_{\mathrm{D}} / \mathrm{V}_{\mathrm{T}}\right)$ as a function of $\dot{V} \mathrm{O}_{2} \%$ predicted maximum. (G) Respiratory frequency/tidal volume $\left(R R / V_{T}\right)$ indicating the rapid shallow breathing index as a function of $\dot{V} \mathrm{O}_{2} \%$ predicted maximum. $(\mathbf{H})$ Borg scores at peak exercise normalized with peak $\dot{\mathrm{V}} \mathrm{O}_{2}$ indicating perception of dyspnea as a function of $\dot{\mathrm{V}} \mathrm{O}_{2} \%$ predicted maximum. All circles indicate the group mean at rest, anaerobic threshold, and peak exercise, respectively; bars indicate standard errors. Between-group comparisons: $* P<0.05$; $* * P<0.0$ I; $* * * P \leq 0.00$ I.

Abbreviations: COPD, chronic obstructive pulmonary disease; IPO, impaired peripheral oxygenation; max, maximum; pred, predicted. 


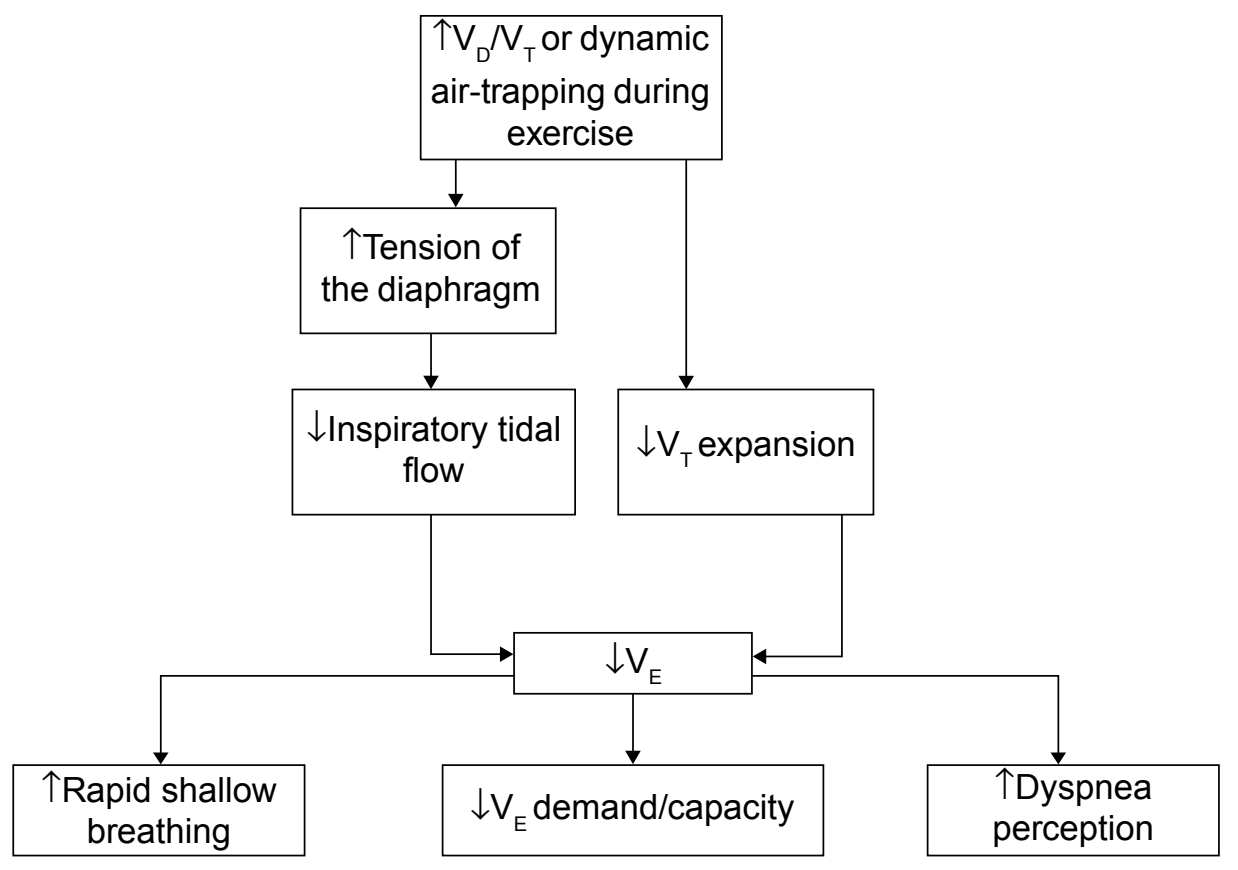

Figure 2 Flow chart showing the deductive mechanism of ventilatory dysfunction and perception of dyspnea at peak exercise in patients with chronic obstructive pulmonary disease complicated with impaired peripheral oxygenation.

Notes: $\uparrow$, increased; $\downarrow$, decreased. Increased or decreased means increase or decrease when compared to the non-IPO group.

Abbreviations: $V_{D} / V_{T}$, dead space to tidal volume ratio; $\dot{V}_{E}$, minute ventilation; $V_{T}$, tidal volume.

\section{Study limitations}

There are a number of limitations in this study that are worthy of note. First, our COPD cohort was comprised exclusively of males, and as such the results cannot be extrapolated to females. However, it should be noted that the incidence of COPD is relatively low in Taiwanese females. Second, IPO includes impairment of cardiac, hemoglobin, and/or peripheral vascular function, and as a result, IPO cannot be fully evaluated by two-dimensional echocardiography. Further study of the peripheral circulation using near-infrared spectroscopy during exercise might be helpful. ${ }^{36}$ Moreover, cardiac function at rest as evaluated by two-dimensional echocardiography may not represent cardiac function during exercise. However, performing an echocardiographic examination while the subject is exercising is technically difficult. Stress echocardiography using pharmacological agents is feasible; however, cardiac performance using this modality is different from that seen during exercise. Third, the patient grouping in this study is not precise, given that some patients in the non-IPO group had abnormal values in some of the variables relevant to IPO. Since none of our 57 patients had all six variables in the normal range, 1,000 patients or more would be required to identify 20 with normal values in all six variables. Fourth, one may argue that using $\dot{\mathrm{V}}_{\mathrm{E}} / \dot{\mathrm{V}} \mathrm{CO}_{2}$ alone instead of the six IPO-related variables might draw similar conclusions to the study. However, this is another issue, and $\dot{\mathrm{V}}_{\mathrm{E}} / \dot{\mathrm{V}} \mathrm{CO}_{2}$ alone cannot represent IPO. Finally, this study did not evaluate intrapulmonary shunt during exercise, although this may not be an issue given that there was no difference in partial pressure of arterial oxygen at peak exercise between the two groups (IPO $68.6 \pm 13.1 \mathrm{mmHg}$ versus non-IPO group $71 \pm 15.1 \mathrm{mmHg}$, not statistically significant). ${ }^{37}$

\section{Conclusion}

Although the six variables used herein are related to IPO or circulatory function, they are inconsistent with the findings of twodimensional echocardiography and $\Delta$ lactate $/ \Delta \mathrm{V}_{2}$ in patients with COPD. Further analysis shows that the mechanisms of exercise intolerance in COPD-IPO patients are primarily due to derangements in airflow and/or dead space ventilation. Given the strength of our findings, this study might help with the interpretation of CPET reports for COPD patients.

\section{Acknowledgments}

This study was supported in part by the Chung Shan Medical University Hospital Research Program (CSHRP 11144, CSH-2012-C-023) and the Chang Gung Medical Research Program (CMRP 443). The authors thank Fen-Chiung Lin, Chang Gung Memorial Hospital, Taoyuan, Taiwan, Republic of China, and Hsiu-Ching Yu, Chung Shan Medical University Hospital Taichung, Taiwan, Republic of China, for performing the two-dimensional echocardiography. 


\section{Disclosure}

The authors report no conflicts of interest in this work.

\section{References}

1. Wasserman K, Hansen JE, Sue DY, Stringer WW, Whipp BJ. Principles of interpretation: a flowchart approach. In: Wasserman K, editor. Principles of Exercise Testing and Interpretation. 4th ed. Philadelphia, PA, USA: Lippincott Williams \& Wilkins; 2005.

2. Louvaris Z, Kortianou EA, Spetsioti S, et al. Intensity of daily physical activity is associated with central hemodynamic and leg muscle oxygen availability in COPD. J Appl Physiol (1985). 2013;115(6):794-802.

3. Chuang ML, Chang HC, Lim KE, Vintch JR. Gas exchange detection of right-to-left shunt in dyspneic patients: report of three cases. Int $J$ Cardiol. 2006;108(1):117-119.

4. McNicholl DM, Megarry J, McGarvey LP, Riley MS, Heaney LG. The utility of cardiopulmonary exercise testing in difficult asthma. Chest. 2011;139(5):1117-1123.

5. Zavala D. Manual of Exercise Testing: A Training Handbook. 2nd ed. Iowa City, IA, USA: University of Iowa Press; 1987.

6. American Thoracic Society; American College of Chest Physicians. ATS/ACCP statement on cardiopulmonary exercise testing. Am J Respir Crit Care Med. 2003;167(2):211-277.

7. Holverda S, Bogaard HJ, Groepenhoff H, Postmus PE, Boonstra A, Vonk-Noordegraaf A. Cardiopulmonary exercise test characteristics in patients with chronic obstructive pulmonary disease and associated pulmonary hypertension. Respiration. 2008;76(2):160-167.

8. Pynnaert C, Lamotte M, Naeije R. Aerobic exercise capacity in COPD patients with and without pulmonary hypertension. Respir Med. 2010; 104(1):121-126.

9. Wasserman K, Hansen JE, Sue DY, Stringer WW, Whipp BJ. Pathophysiology of disorders limiting exercise. In: Wasserman K, editor. Principles of Exercise Testing and Interpretation. 4th ed. Philadelphia, PA, USA: Lippincott Williams \& Wilkins; 2005.

10. Global Initiative for Chronic Obstructive Lung Disease. Global Strategy for the Diagnosis, Management, and Prevention of Chronic Obstructive Pulmonary Disease (revised 2011). Available from: www.goldcopd. org. Accessed December 18, 2014.

11. American Thoracic Society/European Respiratory Society. ATS/ERS statement on respiratory muscle testing. Am JRespir Crit Care Med. 2002; 166(4):518-624.

12. Miller MR, Crapo R, Hankinson J, et al. General considerations for lung function testing. Eur Respir J. 2005;26(1):153-161.

13. Miller MR, Hankinson J, Brusasco V, et al. Standardisation of spirometry. Eur Respir J. 2005;26(2):319-338.

14. Wasserman K, Hansen JE, Sue DY, Stringer WW, Whipp BJ. Clinical exercise testing. In: Wasserman K, editor. Principles of Exercise Testing and Interpretation. 4th ed. Philadelphia, PA, USA: Lippicott Williams \& Wilkins; 2005.

15. Chuang ML, Lee CH, Lin IF. Using the oxygen-cost diagram in ramp-slope selection for dyspneic patients. Intern Med. 2010;49(14):1325-1332.

16. Chuang ML, Lin IF. Clinical characteristics and lung function in chronic obstructive pulmonary disease complicated with impaired peripheral oxygenation. Intern Emerg Med. 2014;9(6):633-640.

17. Wasserman K, Hansen JE, Sue DY, Stringer WW, Whipp BJ. Normal values. In: Wasserman K, editor. Principles of Exercise Testing and Interpretation. 4th ed. Philadelphia, PA, USA: Lippincott Williams \& Wilkins; 2005.

18. O'Donnell DE, Voduc N, Fitzpatrick M, Webb KA. Effect of salmeterol on the ventilatory response to exercise in chronic obstructive pulmonary disease. Eur Respir J. 2004;24(1):86-94.

19. Yang KL, Tobin MJ. A prospective study of indexes predicting the outcome of trials of weaning from mechanical ventilation. $N$ Engl $J$ Med. 1991;324(21):1445-1450.
20. Bertoli L, Mantero A, Cicero SL, Alpago R, Rizzato G, Belli C. Usefulness of two-dimensional echocardiography in the assessment of right heart in chronic obstructive lung disease. Progress in Respiratory Research. 1985;20:91-100.

21. Danchin N, Cornette A, Henriquez A, et al. Two-dimensional echocardiographic assessment of the right ventricle in patients with chronic obstructive lung disease. Chest. 1987;92(2):229-233.

22. Chuang ML, Lin IF, Vintch JR, Ho BS, Chao SW, Ker JJ. Significant exercise-induced hypoxaemia with equivocal desaturation in patients with chronic obstructive pulmonary disease. Intern Med J. 2006; 36(5):294-301.

23. Wasserman K, Hansen JE, Sue DY, Stringer WW, Whipp BJ. Calculations, formulas, and examples. In: Wasserman K, editor. Principles of Exercise Testing and Interpretation. 4th ed. Philadelphia, PA, USA: Lippincott Williams \& Wilkins; 2005.

24. Rosner B, editor. Hypothesis testing: one-sample inference. Fundamentals of Biostatistics. 7th ed. Boston, MA, USA: Brooks/Cole, Cengage Learning; 2011.

25. Oliver RM, Fleming JS, Waller DG. Right ventricular function at rest and during exercise in chronic obstructive pulmonary disease. Comparison of two radionuclide techniques. Chest. 1993;103(1):74-80.

26. Boerrigter BG, Bogaard HJ, Trip P, et al. Ventilatory and cardiocirculatory exercise profiles in COPD: the role of pulmonary hypertension. Chest. 2012;142(5):1166-1174.

27. Come CE, Divo MJ, San Jose Estepar R, et al. Lung deflation and oxygen pulse in COPD: results from the NETT randomized trial. Respir Med. 2012;106(1):109-119.

28. Montes de Oca M, Rassulo J, Celli BR. Respiratory muscle and cardiopulmonary function during exercise in very severe COPD. Am J Respir Crit Care Med. 1996;154(5):1284-1289.

29. Tzani P, Aiello M, Elia D, et al. Dynamic hyperinflation is associated with a poor cardiovascular response to exercise in COPD patients. Respir Res. 2011;12:150.

30. Caviedes IR, Delgado I, Soto R. Ventilatory inefficiency as a limiting factor for exercise in patients with COPD. Respir Care. 2011;57(4): 583-589.

31. Benditt JO, Lewis S, Wood DE, Klima L, Albert RK. Lung volume reduction surgery improves maximal $\mathrm{O} 2$ consumption, maximal minute ventilation, $\mathrm{O} 2$ pulse, and dead space-to-tidal volume ratio during leg cycle ergometry. Am J Respir Crit Care Med. 1997;156(2 Pt 1):561-566.

32. Berton DC, Barbosa PB, Takara LS, et al. Bronchodilators accelerate the dynamics of muscle $\mathrm{O}_{2}$ delivery and utilisation during exercise in COPD. Thorax. 2010;65(7):588-593.

33. Dillard TA, Piantadosi S, Rajagopal KR. Determinants of maximum exercise capacity in patients with chronic airflow obstruction. Chest. 1989;96(2):267-271.

34. LoRusso TJ, Belman MJ, Elashoff JD, Koerner SK. Prediction of maximal exercise capacity in obstructive and restrictive pulmonary disease. Chest. 1993;104(6):1748-1754.

35. Mahut B, Chevalier-Bidaud B, Plantier L, et al. Diffusing capacity for carbon monoxide is linked to ventilatory demand in patients with chronic obstructive pulmonary disease. COPD. 2012;9(1):16-21.

36. Mohler ER 3rd, Lech G, Supple GE, Wang H, Chance B. Impaired exercise-induced blood volume in type 2 diabetes with or without peripheral arterial disease measured by continuous-wave near-infrared spectroscopy. Diabetes Care. 2006;29(8):1856-1859.

37. Shaikh ZF, Kelly JL, Shrikrishna D, et al. Patent foramen ovale is not associated with hypoxemia in severe chronic obstructive pulmonary disease and does not impair exercise performance. Am J Respir Crit Care Med. 2014;189(5):540-547. 
International Journal of COPD

\section{Publish your work in this journal}

The International Journal of COPD is an international, peer-reviewed journal of therapeutics and pharmacology focusing on concise rapid reporting of clinical studies and reviews in COPD. Special focus is given to the pathophysiological processes underlying the disease, intervention programs, patient focused education, and self management protocols.

This journal is indexed on PubMed Central, MedLine and CAS. The manuscript management system is completely online and includes a very quick and fair peer-review system, which is all easy to use. Visit $\mathrm{http}: / / \mathrm{www}$.dovepress.com/testimonials.php to read real quotes from published authors.

Submit your manuscript here: http://www.dovepress.com/international-journal-of-chronic-obstructive-pulmonary-disease-journal 